\title{
Long term results of hepatic resection or orthotopic liver transplantation in patients with liver metastases from gastrointestinal neuroendocrine tumors
}

\author{
ENRICO MARIA PASQUAL ${ }^{1}$, SERENA BERTOZZI ${ }^{1}$, AMBROGIO P. LONDERO $^{2}$, STEFANO BACCHETTI $^{1}$, \\ DARIO LORENZIN ${ }^{1}$, ALBERTO PASQUALUCCI $^{3}$, FEDERICO MOCCHEGGIANI $^{4}$, \\ ALEN FEDERICI $^{4}$, MARCO VIVAVERLLI $^{4}$ and ANDREA RISALITI ${ }^{1}$

\begin{abstract}
${ }^{1}$ Department of Surgery, University of Udine - DISM - DSMB, 'Santa Maria della Misericordia' University Hospital, I-33100 Udine; ${ }^{2}$ Unit of Obstetrics and Gynecology, 'S. Polo' Hospital, I-34074 Monfalcone; ${ }^{3}$ Department of Anaesthesiology, University of Perugia, I-06123 Perugia; ${ }^{4}$ Department of Surgery, Marche Polytechnic University,
\end{abstract} \\ 'Ospedali Riuniti Umberto I, G.M. Lancisi, G. Salesi' University Hospital, I-60123 Ancona, Italy
}

Received April 12,2015; Accepted August 8, 2016

DOI: $10.3892 / \mathrm{ol} .2016 .5045$

\begin{abstract}
Hepatic metastases are one of the most important prognostic factors for survival among patients affected by gastrointestinal neuroendocrine tumors (NETs). The present study aims to evaluate the impact of surgery, including hepatic resection or orthotopic liver transplantation (OLT), on the outcome of patients affected by hepatic metastases from NETs, in terms of overall survival (OS). In this multicentric retrospective study, data was collected on 26 patients, who underwent surgery for hepatic metastases from NETs in two Italian University Clinics between January 1990 and December 2012; of which, 22 patients underwent hepatic resective surgery and 4 patients OLT. Hepatic metastases were synchronous in the $53.8 \%$ of cases and metachronous in the $46.2 \%$ of cases. The median number of resected hepatic metastases was 3. Surgical radicalness (R0) was reached in the $84.6 \%$ of cases. In total, $57.7 \%$ of patients had a recurrence, $66.7 \%$ of which were intra- and $33.3 \%$ extra-hepatic. The OS of patients that underwent hepatic resections and OLT was $44.9 \%$ [95\% confidence interval (CI95), 26.0-77.7\%] and 50\% (CI95, 12.5-100.0\%) at 5 years, respectively. Although the data regarding the survival of patients receiving surgery for hepatic
\end{abstract}

Correspondence to: Professor Enrico Maria Pasqual, Department of Surgery, University of Udine - Department of Experimental and Clinical Medical Sciences, 'Santa Maria della Misericordia', University Hospital, Piazzale Santa Maria della Misericordia 15, I-33100 Udine, Italy

E-mail: dr.bertozzi@gmail.com

Abbreviations: NET, neuroendocrine tumor; OLT, orthotopic liver transplantation

Key words: gastroenteropancreatic neuroendocrine tumors, liver metastases, orthotopic liver transplantation, hepatic resection, overall survival metastases from NETs are encouraging, randomized clinical trials are necessary to more adequately evaluate the effect of surgery on survival of this group of patients.

\section{Introduction}

Neuroendocrine tumors (NETs) include numerous heterogeneous types of cancers with extremely varied biological behaviors (1-3). The literature published on the subject commonly divides NETs into two major classes, based on their primary origin: Pancreatic neuroendocrine (islet cell) tumors and gastrointestinal neuroendocrine tumors (carcinoids) (4-6). In particular, gastrointestinal NETs are usually characterized by a slow growth pattern, are commonly diagnosed in the advanced stages of disease (5,7-12), and present with liver metastases in $50-75 \%$ of cases (13-15).

The frequent occurrence of liver secondaries in patients affected by gastrointestinal NETs is a clear sign of clinical controversy. NETs represent a rare group of neoplastic diseases; therefore, affected patients are recommended to be transferred into larger, more experienced centers that can more appropriately treat rare hepatic metastasis. Furthermore, although metastatic malignancies were once commonly considered as a terminal neoplastic stage, numerous therapeutic options have now been introduced in order to improve the quantity and quality of life in patients affected by rare liver metastasis $(11,16-18)$.

However, the role of liver surgery for patients with metastatic gastrointestinal NETs remains an argument of great debate; the inert growth and long term natural history of gastrointestinal NETs makes determining the real effectiveness of the hepatic surgical approach on overall survival (OS) even more challenging. In particular, in an analysis of 13,715 patients conducted by Modlin et al (3), synchronous distant metastases were already evident in the $12.9 \%$ of patients with gastrointestinal NETs, and demonstrated a 5-year OS rate of $67.2 \%$. As a consequence, the widely promulgated benignity of these neoplasms has been brought into question, 
so that the current literature recognizes their malignant potential (2,19-22).

In patients with NETs, the occurrence of hepatic secondaries is one of the most important prognostic factors for survival (11,23-25). Therefore, the present study aims to evaluate the impact of surgery, including hepatic resection and orthotopic liver transplantation (OLT), on the outcome of patients affected by hepatic metastases from NETs, in terms of OS.

\section{Materials and methods}

Data collection. For this multicentric retrospective study, data was collected on 26 patients, who underwent surgery for hepatic metastases from NETs at the Departments of Surgery of 'Santa Maria della Misericordia' University Hospital (Udine, Italy) and 'Ospedali Riuniti Umberto I, G.M. Lancisi, G. Salesi’ University Hospital (Ancona, Italy) between January 1990 and December 2012; of which, 22 patients underwent hepatic resective surgery and 4 underwent OLT. In the present study, only patients treated with surgical treatment were considered; as a result, none of the included patients underwent intraoperative treatments associated with surgical resection.

The present study was conducted in accordance with the Declaration of Helsinki and following the dictates of the general authorization to process personal data for scientific research purposes by the Italian Data Protection Authority (Rome, Italy). Furthermore, the present study was also approved by the Internal Review Board of the Department of Experimental and Clinical Medical Sciences, University of Udine (Udine, Italy).

Data collection took into consideration patients' characteristics (age at diagnosis, presence of symptoms, bioumoral markers and imaging findings), tumor characteristics (histotype, stage, primary tumor and secondary localizations), and treatments (hepatic resections or OLT). The main outcome considered in the present study was the OS of the included patients.

Patient profiling. The imaging techniques used to diagnose and stage patients affected by NETs included chest-abdominal-pelvic computerized tomography (CT) scans, magnetic resonance imaging (MRI), octreoscan and positron emission tomography- computed tomography (PET/CT) with 111In-pentetreotide. CT or PET/CT scans obtained by initial diagnosis were also used to determine the percentage of diseased hepatic parenchyma. In addition, hepatic parenchyma involvement was divided into lobar and bi-lobar, and the major diameter of the greatest hepatic metastasis was also registered.

Every patient was investigated for the presence of symptoms, including tachycardia or flushing. Among the bioumoral markers of NETs, the following were routinely preoperatively tested: Urinary vanilmandelic acid dosage in the $24 \mathrm{~h}$; urinary catecolamine dosage; urinary 5-idrossi-indolo-acetic acid dosage; seric cromogranin A; seric neuronal specific enolase; seric insulin; seric glucagon; seric gastrin; seric vasoactive intestinal peptide; and seric somatostatin. To complete the preoperative assessment of patients, an electrocardiograph and endocrinological, oncological and anaesthesiological evaluations were also undertaken.
Patients with unresectable hepatic metastases were candidates for OLT, and were required to satisfy the following inclusion criteria: Histological confirmation of NET; diffuse unresectable hepatic disease; substitution of $\leq 50 \%$ hepatic parenchyma; stable disease during the preoperative period; absent or stable extra-hepatic disease during the preoperative period; and hepatic insufficiency following the hepatic resection of stable disease (rescue OLT).

For the follow-up, bioumoral markers were tested at 3,6 and 12 months, where appropriate. The instrumental follow-up consisted of imaging repetition after 6 and 12 months from surgery. All patients included in the present study were monitored for at least 12 months following surgery. For patients that were monitored for $>12$ months, bioumoral markers and imaging were then assessed yearly for the first 5 years, or more frequently in case of recurrence suspicion.

Statistical analysis. Statistical analysis was performed using R (version 3.0.1; www.r-project.org; The R Foundation for Statistical Computing, Vienna, Austria). Distribution normality was evaluated through the Kolmogorov-Smirnov test. In addition, the following statistical tests were applied where appropriate: Student's $t$-test, Wilcoxon test, one way analysis of variance and Kruskal-Wallis test for continuous variables; chi-square test and Fisher's exact test for categorical variables. To analyze the OS of patients, Kaplan-Meier curves were drawn, and the differences between various groups were tested using the Log-rank test.

\section{Results}

Description of the population. In total, 26 patients, whose characteristics are exhibited in Table I, received surgery for hepatic metastases from NETs. The mean age at the diagnosis of hepatic metastases was $58.04 \pm 13.05$ years, $59.73 \pm 12.78$ years for patients that received hepatic resections and $48.75 \pm 11.84$ years for those that underwent OLT. Among the patients that received surgery, vasomotoric symptoms were reported in 4 cases $(15.4 \%)$. Primary tumors were located in the pancreas in 8 cases $(30.8 \%)$ and in the ileum in 6 cases $(23.1 \%)$.

In $53.8 \%$ of cases (14/26), hepatic metastases were synchronous, 13 cases of which were surgically treated together with the primary tumor. For these patients, the majority of cases received a partial pancreasectomy $(35.7 \%, 5 / 14)$, followed in terms of prevalence by gastrectomy $(21.4 \%, 3 / 14)$, right emicolectomy $(21.4 \%, 3 / 14)$ and ileal resection $(14.3 \%, 2 / 14)$. In one case, an ileal resection and liver transplantation were performed in two different surgeries. Extra-hepatic metastases were present in $30.8 \%$ of patients $(8 / 26)$, with the most secondary cases occurring in the lymph nodes $(62.5 \%, 5 / 8)$ and bone $(37.5 \%, 3 / 8)$.

Characteristics of hepatic metastases. Hepatic metastases were synchronous in the $53.8 \%$ of cases and metachronous in the $46.2 \%$ of cases. Metachronous hepatic secondaries were diagnosed in $80 \%$ of cases within 4 years from the primary tumor resection, at a median time interval of 13 months (range, 6-40 months).

The median number of hepatic metastases was 3 [interquartile range (IQR), 2-6], ranging between 1-23. The hepatic 
Table I. Description of the population $(n=26)$.

\begin{tabular}{|c|c|}
\hline Characteristic & $\begin{array}{c}\text { No. of } \\
\text { patients }(\%)\end{array}$ \\
\hline Age at diagnosis, years ${ }^{\mathrm{a}}$ & $58.04 \pm 13.05$ \\
\hline Length of follow-up, months ${ }^{b}$ & $24(13-58)$ \\
\hline Gender, male & $12(46.2)$ \\
\hline $\begin{array}{l}\text { Symptoms associated with carcinoid } \\
\text { syndrome }\end{array}$ & $4(15.4)$ \\
\hline Presence of synchronous liver metastases & $14(53.8)$ \\
\hline Presence of extra-hepatic metastases ${ }^{c}$ & $8(30.8)$ \\
\hline Lymph nodes & $5(62.5)$ \\
\hline Bones & $3(37.5)$ \\
\hline Lungs & $2(25.0)$ \\
\hline Brain & $1(12.5)$ \\
\hline Mediastinum & $1(12.5)$ \\
\hline \multicolumn{2}{|l|}{$\begin{array}{l}\text { Surgical treatment for primary tumor in cases } \\
\text { with synchronous liver metastasis }(n=14)\end{array}$} \\
\hline Gastrectomy & $3(21.4)$ \\
\hline Ileal resection & $3(21.4)$ \\
\hline Right hemicolectomy & $3(21.4)$ \\
\hline Resection of the rectum & $1(7.1)$ \\
\hline Partial pancreatectomy & $5(35.7)$ \\
\hline \multicolumn{2}{|l|}{ Surgical treatment of liver metastases ${ }^{\mathrm{d}}$} \\
\hline Hepatic resections & $22(84.6)$ \\
\hline Partial right hepatectomy & $1(4.5)$ \\
\hline Partial left hepatectomy & $0(0.0)$ \\
\hline Single hepatic segmentectomy & $1(4.5)$ \\
\hline Multiple hepatic segmentectomies & $1(4.5)$ \\
\hline Wedge excision & $20(90.9)$ \\
\hline Orthotopic liver transplantation & $4(15.4)$ \\
\hline Number of hepatic wedge resections ${ }^{\mathrm{b}}$ & $3(2-6)$ \\
\hline Maximum tumor diameter, $\mathrm{cm}^{\mathrm{e}}$ & $6(3-8)$ \\
\hline Post-surgical complications & $3(11.5)$ \\
\hline \multicolumn{2}{|l|}{ Localization of the primary tumor } \\
\hline Stomach & $4(15.4)$ \\
\hline Esophagus & $1(3.8)$ \\
\hline Duodenum & $2(7.7)$ \\
\hline Ileum & $6(23.1)$ \\
\hline Pancreas & $8(30.8)$ \\
\hline Colon & $3(11.5)$ \\
\hline Lung & $1(3.8)$ \\
\hline Unknown primary & $1(3.8)$ \\
\hline
\end{tabular}

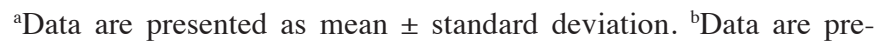
sented as median (IQR). ' In 3 cases there were multiple locations of extra-hepatic metastases. In 1 case of partial hepatectomy, a resection wedge was also performed. ${ }^{e}$ Data are presented as median (IQR). $\mathrm{IQR}$, interquartile range.

metastases were localized in a single hepatic segment in the $15.4 \%$ of cases $(4 / 26)$, in $>1$ segment within the same hepatic lobe in the $30.8 \%$ of cases $(8 / 26)$, and diffused to both lobes in the $53.8 \%$ of cases $(14 / 26)$. The final group mentioned includes all four patients that underwent OLT.

Surgical treatment of hepatic metastases. The majority of patients $(84.6 \%, 22 / 26)$ underwent a hepatic resection, which, in the majority of cases, was a wedge metastasectomy (90\%, 20/22) (Table I). In 50\% of cases, $>3$ resections were performed. The mean diameter of the greatest resected metastasis was $6 \mathrm{~cm}$ (IQR, 3-8 cm).

Complete hepatic disease resection was reached in the $84.6 \%$ of patients $(22 / 26)$, whereas residual hepatic disease was classified as microscopic in 3 cases (11.5\%) and macroscopic in one single case $(3.8 \%)$. For patients that received typical (lobectomy, segmentectomy or pluri-segmentectomy) and atypical hepatic resections (wedge resection or metastasectomy), complete hepatic disease resection was reached in $66.7 \%(2 / 3)$ and $84.2 \%(16 / 19)$ of cases, respectively. No residual disease was left in all four transplanted patients. For patients with hepatic complete disease resections, the 5-year OS rate was $58.4 \%$ (95\% CI, 38.0-90.0\%), while the 5-year OS rate for patients with microscopic or macroscopic hepatic residual disease the was $0 \%(\mathrm{P}=0.0003)$.

The mean length of surgery was $4.94 \pm 0.83 \mathrm{~h}$, the mean recovery length was $10.60 \pm 4.67$ days, and $71 \%$ of patients required a recovery in the intensive care unit in the immediate post-operative time. Post-operative complications affected $11.5 \%$ of patients $(3 / 26)$, including intra-abdominal bleeding, intra-abdominal sero-hematic collections, pleural effusion and pancreatic fistula, which for only $1 / 3$ cases required a surgical re-intervention. Another patient should be included among surgical complications, a woman that experienced a dramatic post-operative diffuse hepatic necrosis required an urgent rescue OLT; however, this case has been considered among the 4 cases of OLT and resulted in no complications following transplantation. In only 1 case of OLT (right lobe living related liver transplantation, already presented as a case report), liver failure was registered at the 1 year follow-up, due to intrahepatic multiple arterio-portal fistulas (26). The patient later succumbed while waiting for a rescue re-transplantation, and at the time of liver failure this patient was free of disease.

No significant differences were identified between patients that received hepatic resections and those that underwent OLTs (Table II). Furthermore, considering the differences between people that survived and passed away, only an increased prevalence of extra-hepatic metastases were observed in patients that had passed away compared with patients that remained alive at 5 years subsequent to surgery $(\mathrm{P}=0.064)$.

The OS rate at 5 years was $47.2 \%$ (95\% CI, 28.8-77.1\%) (Fig. 1A). Fig. 1B shows the OS rates of patients with and without extra-hepatic metastases at 5 years $[25.0 \%(95 \% \mathrm{CI}$, 7.5-83.0\%) and 54.8\% (95\% CI, 31.1-96.7\%), respectively], which were found to be significantly different $(\mathrm{P}=0.012)$.

In Fig. $1 C$ and D, the OS rates were compared between patients that received OLTs and hepatic resections, with hepatic resections subdivided into synchronous and metachronous ones in Fig. 1C, and no significant differences were observed in either case. In Fig. 1D the OS rates of patients that underwent hepatic resections and OLTs were $44.9 \%(95 \%$ CI, 26.0-77.7\%) and 50\% (95\% CI, 12.5-100.0\%) at 5 years, respectively $(\mathrm{P}=0.651)$. 
Table II. Description of the population in patients treated with hepatic resection $(n=22)$ or OLT $(n=4)$.

Characteristic

Hepatic resections,

OLT,

Age at diagnosis, years ${ }^{\mathrm{a}}$ no. of patients $(\%)$

no. of patients $(\%)$

P-value

Length of follow-up, months ${ }^{b}$

\section{$59.73 \pm 12.78$}

$26(10-58)$

Gender, male

$12(54.5)$

Symptoms associated with carcinoid syndrome

$12(54.5)$

Post-surgical complications

Localization of the primary tumor

Stomach

Esophagus

Duodenum

Ileum

Pancreas

Colon

Lung

Unknown primary
2 (9.1)

6 (27.3)

4 (66.7)

2 (33.4)

2 (33.4)

$1(16.7)$

1 (16.7)

2 (9.1)

$\begin{array}{cc}48.75 \pm 11.84 & 0.161 \\ 16(14-33) & 0.670 \\ 0(0.0) & 0.100 \\ 2(50.0) & 0.099 \\ 2(50.0) & 0.867 \\ 2(50.0) & 0.563 \\ 1(50.0) & 1.000 \\ 1(50.0) & 0.673 \\ 0(0.0) & 0.346 \\ 0(0.0) & 0.537 \\ 0(0.0) & 0.537 \\ 1(25.0) & 0.408\end{array}$

4 (18.2)

$0(0.0)$

0.354

$1(4.5)$

$0(0.0)$

0.664

2 (9.1)

$0(0.0)$

0.530

3 (13.6)

3 (75.0)

$<0.050$

7 (31.8)

3 (13.6)

$1(25.0)$

0.786

$0(0.0)$

0.432

1 (4.5)

$0(0.0)$

0.664

1 (4.5)

$0(0.0)$

0.664

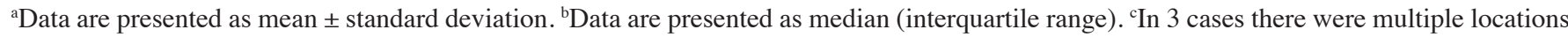
of extra-hepatic metastases. OLT, orthotopic liver transplantation.
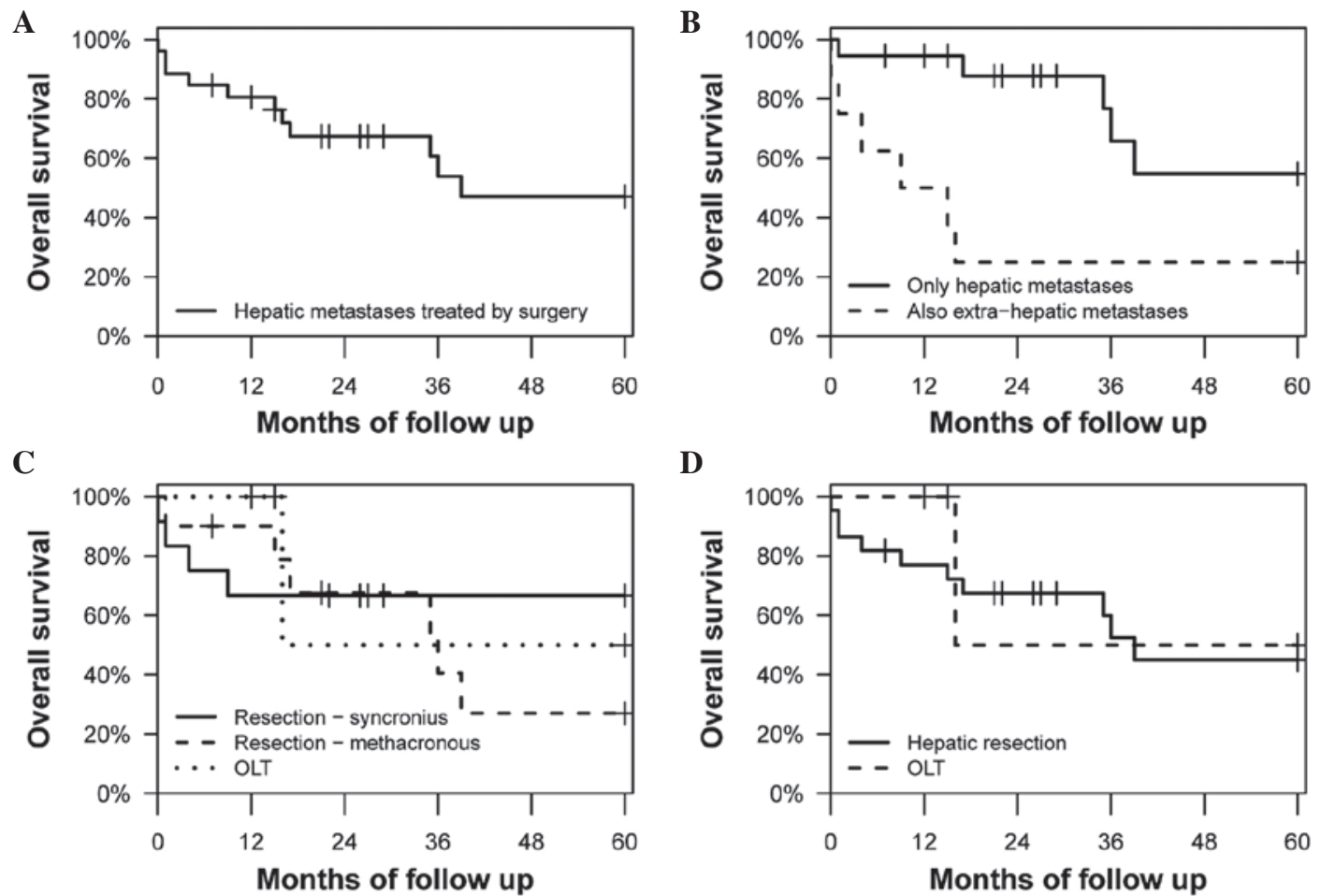

D

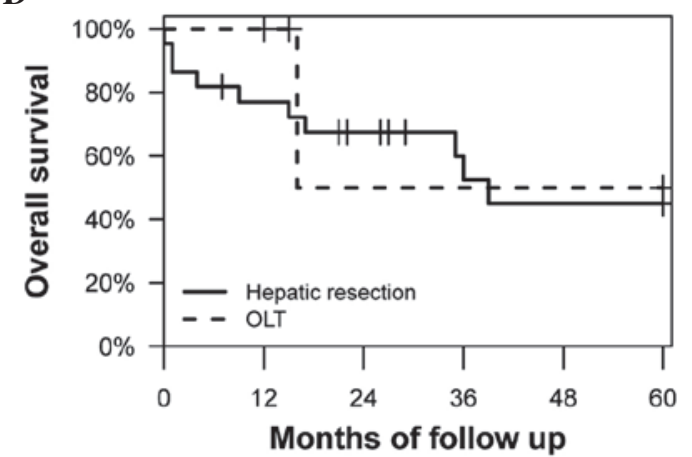

Figure 1. Kaplan-Meier curves depicting: (A) Overall survival rate of all the 26 cases analyzed; (B) overall survival of patients with liver metastases alone and patients with liver metastasis and extra-hepatic metastases; (C) patients with synchronous or metachronous liver metastases and different surgical treatment; (D) differences between patients with hepatic resection and OLT. OLT, orthotopic liver transplantation. 
Table III. Description of the population in patients with metachronous $(n=12)$ or synchronous $(n=14)$ liver metastases.

\begin{tabular}{|c|c|c|c|}
\hline Characteristic & $\begin{array}{c}\text { Metachronous metastases, } \\
\text { no. of patients }(\%)\end{array}$ & $\begin{array}{c}\text { Synchronous metastases, } \\
\text { no. of patients }(\%)\end{array}$ & P-value \\
\hline Age at diagnosis, years ${ }^{\mathrm{a}}$ & $60.50 \pm 11.56$ & $53.07 \pm 15.43$ & 0.174 \\
\hline Length of follow-up, months ${ }^{b}$ & $28(15-46)$ & $24(10-56)$ & 0.758 \\
\hline Gender, male & $7(58.3)$ & $5(35.7)$ & 0.249 \\
\hline Symptoms associated with carcinoid syndrome & $0(0.0)$ & $4(28.6)$ & 0.100 \\
\hline Presence of extra-hepatic metastases ${ }^{c}$ & $4(33.3)$ & $4(28.6)$ & 0.793 \\
\hline Lymph nodes & $2(50.0)$ & $3(75.0)$ & 1.000 \\
\hline Bones & $1(25.0)$ & $2(50.0)$ & 0.465 \\
\hline Lungs & $0(0.0)$ & $2(50.0)$ & 0.102 \\
\hline Brain & $1(25.0)$ & $0(0.0)$ & 0.285 \\
\hline Mediastinum & $1(25.0)$ & $0(0.0)$ & 0.285 \\
\hline \multicolumn{4}{|l|}{ Surgical treatment of liver metastases ${ }^{\mathrm{d}}$} \\
\hline Hepatic resections & $10(83.3)$ & $12(85.7)$ & 0.867 \\
\hline Partial right hepatectomy & $1(10.0)$ & $0(0.0)$ & 0.262 \\
\hline Partial left hepatectomy & $0(0.0)$ & $0(0.0)$ & 1.000 \\
\hline Single hepatic segmentectomy & $1(10.0)$ & $0(0.0)$ & 0.262 \\
\hline Multiple hepatic segmentectomies & $0(0.0)$ & $1(8.3)$ & 0.350 \\
\hline Wedge excision & $9(90.0)$ & $11(91.7)$ & 0.892 \\
\hline Orthotopic liver transplantation & $2(16.7)$ & $2(14.3)$ & 0.867 \\
\hline Maximum tumor diameter, $\mathrm{cm}^{\mathrm{e}}$ & $6(4-8)$ & $6(3-8)$ & 1.000 \\
\hline Post-surgical complications & $0(0.0)$ & $3(21.4)$ & 0.225 \\
\hline \multicolumn{4}{|l|}{ Localization of the primary tumor } \\
\hline Stomach & $2(16.7)$ & $2(14.3)$ & 0.867 \\
\hline Esophagus & $0(0.0)$ & $1(7.1)$ & 0.345 \\
\hline Duodenum & $1(8.3)$ & $1(7.1)$ & 0.910 \\
\hline Ileum & $2(16.7)$ & $4(28.6)$ & 0.473 \\
\hline Pancreas & $4(33.3)$ & $4(28.6)$ & 0.973 \\
\hline Colon & $1(8.3)$ & $2(14.3)$ & 0.636 \\
\hline Lung & $1(8.3)$ & $0(0.0)$ & 0.271 \\
\hline Unknown primary & $1(8.3)$ & $0(0.0)$ & 0.271 \\
\hline
\end{tabular}

${ }^{a}$ Data are presented as mean \pm standard deviation. ${ }^{b}$ Data are presented as median (IQR). ${ }^{c}$ In 3 cases there were multiple locations of extra-hepatic metastases. ${ }^{\mathrm{d} I n} 1$ case of partial hepatectomy, a wedge resection was also performed. ${ }^{\mathrm{e}}$ Data are presented as median (IQR). IQR, interquartile range.

Table III evaluates the differences between patients with synchronous and metachronous hepatic metastases, and Table IV compares the patients with or without extra-hepatic metastases. Also in these cases, no significant differences have been highlighted. Recurrences affected $57.7 \%$ of the patients studied. In particular, among patients with a recurrence, $66.7 \%$ experienced a hepatic recurrence and a single case was successfully re-resected, whereas $33.3 \%$ of the patients had an extra-hepatic recurrence for which a palliative systemic treatment was undertaken.

\section{Discussion}

Hepatic metastases were synchronous in $53.8 \%$ of cases and metachronous in $46.2 \%$ of cases. The median number of resected hepatic metastases was 3. Complete resection of hepatic disease was achieved in $84.6 \%$ of cases. Recurrences were observed in $57.7 \%$ of patients, of which $66.7 \%$ were intra-hepatic and $33.3 \%$ extra-hepatic. Post-operative complications affected $11.5 \%$ of patients, but required re-intervention in a single case. The OS rates of patients that underwent hepatic resections and OLTs were $44.9 \%$ (95\% CI, 26.0-77.7\%) and $50.0 \%$ (95\% CI, $12.5-100.0 \%)$ at 5 years following surgery, respectively.

There is currently no accordance regarding the best therapeutic management of patients with non-resectable liver metastases from NETs; however, numerous non-surgical treatments have been developed in order to provide a chance of survival. The treatments that may be employed, which are currently considered as palliative options, include biotherapy with somatostatin analogs, peptide-mediated radioreceptor therapy, transarterial chemoembolisation, selective 
Table IV. Differences between patients with hepatic metastases only $(n=18)$ and patients with hepatic and extra-hepatic metastases $(n=8)$.

\begin{tabular}{|c|c|c|c|}
\hline Characteristic & $\begin{array}{l}\text { Hepatic metastases only, } \\
\text { no. of patients }(\%)\end{array}$ & $\begin{array}{c}\text { Hepatic and extra-hepatic } \\
\text { metastases, no. of patients (\%) }\end{array}$ & P-value \\
\hline Age at diagnosis, years ${ }^{a}$ & $56.39 \pm 15.2$ & $56.75 \pm 11.91$ & 0.949 \\
\hline Length of follow-up, months ${ }^{\mathrm{b}}$ & $28(18-58)$ & $12(3-28)$ & 0.071 \\
\hline Gender, male & $8(44.4)$ & $4(50.0)$ & 0.793 \\
\hline Symptoms associated with carcinoid syndrome & $2(11.1)$ & $2(25.0)$ & 0.365 \\
\hline Post-surgical complications & $2(11.1)$ & $1(12.5)$ & 0.919 \\
\hline Presence of synchronous liver metastases & $10(55.6)$ & $4(50.0)$ & 0.793 \\
\hline \multicolumn{4}{|l|}{ Surgical treatment of liver metastases ${ }^{c}$} \\
\hline Hepatic resections & $16(88.9)$ & $6(75.0)$ & 0.365 \\
\hline Partial right hepatectomy & $0(0.0)$ & $1(16.7)$ & 0.095 \\
\hline Partial left hepatectomy & $0(0.0)$ & $0(0.0)$ & 1.000 \\
\hline Single hepatic segmentectomy & $1(6.2)$ & $0(0.0)$ & 0.531 \\
\hline Multiple hepatic segmentectomies & $1(6.2)$ & $0(0.0)$ & 0.531 \\
\hline Wedge excision & $14(87.5)$ & $6(100.0)$ & 0.364 \\
\hline Orthotopic liver transplantation & $2(11.1)$ & $2(25.0)$ & 0.365 \\
\hline Maximum tumor diameter, $\mathrm{cm}^{\mathrm{d}}$ & $6(2-10)$ & $6(4-7)$ & 1.000 \\
\hline \multicolumn{4}{|l|}{ Localization of the primary tumor } \\
\hline Stomach & $3(16.7)$ & $1(12.5)$ & 0.786 \\
\hline Esophagus & $0(0.0)$ & $1(12.5)$ & 0.126 \\
\hline Duodenum & $2(11.1)$ & $0(0.0)$ & 0.326 \\
\hline Ileum & $4(22.2)$ & $2(25.0)$ & 0.877 \\
\hline Pancreas & $6(33.3)$ & $2(25.0)$ & 0.671 \\
\hline Colon & $2(11.1)$ & $1(12.5)$ & 0.919 \\
\hline Lung & $1(5.6)$ & $0(0.0)$ & 0.497 \\
\hline Unknown primary & $0(0.0)$ & $1(12.5)$ & 0.126 \\
\hline
\end{tabular}

${ }^{a}$ Data are presented as mean \pm standard deviation. ${ }^{b}$ Data are presented as median (IQR). ${ }^{c}$ In 1 case of partial hepatectomy, a wedge resection was also performed. ${ }^{\mathrm{d}}$ Data are presented as median (IQR). IQR, interquartile range.

intra-arterial radiotherapy and novel molecular target-directed therapy $(6,27,28)$.

Currently, for cases of resectable liver metastases from NETs, the current literature demonstrates surgery to be the most efficient approach $(4,17,18,23,24,29-32)$. In addition, a potentially curative resection of liver secondaries may be undertaken in 13.7-24.5\% of patients with metastatic NETs (33-35). However, although cytoreductive procedures are recognized to have a crucial role among patients with hormonal symptoms, who can consequently have a great benefit from the reduction of secreting mass and a relief from symptoms, the role of such aggressive surgery in case of asymptomatic disease remains a subject of debate. In fact, the majority of patients with liver metastases from NETs recur after hepatic resection, with recurrence rates up to $70-94 \%$ at 5 years $(7,23,25,36-39)$, and the role of repeated operations remains ill-defined (37).

The survival impact of hepatic resection is challenging to assess for several reasons. First, the patient selection criteria for hepatic surgery differed across centers, and the completeness of the resection was not determined clearly in several studies. Second, numerous studies reporting the outcome of surgical management of liver metastases from NETs focused solely on resection rather than combined approaches, such as resection and ablation, and the results of liver resection or other therapies were often not determined separately. Third, as prospective randomized data of surgical resection in metastatic neuroendocrine tumors are lacking, recommendations have to rely on recently published retrospective series. Fourth, the majority of studies provide an analysis of pooled data from a mixed group of NETs, which are of foregut, midgut and hindgut origin.

In the literature, the 5-year OS rate of patients that have received surgery for hepatic metastases from NETs ranges between $67-93 \%$ (29); for cases of surgery with palliative intent, the rate is $64 \%$, and for cases that received conservative non-surgical treatments the rate varies between $18-52 \%$ (29). The 5-year OS rates of the population examined in the present study were 44.9 and $50.0 \%$ for hepatic resections and OLTs, respectively, and therefore lower compared with the data presented in the previous literature (29). However, this finding is probably a consequence of the option for patients that are affected by metachronous metastases to receive palliative 
resections at the Santa Maria della Misericordia' and 'Ospedali Riuniti Umberto I, GM Lancisi, G Salesi’ university hospitals. Furthermore, taking into consideration only patients affected by synchronous metastases, the 5 -year OS rate was $>60 \%$. Moreover, if the rescue OLT is excluded, the 5-year OS rate of transplanted patients was $100 \%$. Finally, the present study showed that, for the differences between hepatic resections and OLT, the results of the surgeries were encouraging and comparable in terms of survival to those of Coppa et al (35). In addition, in a recent publication in Europe, the 5-year OS following OLT was found to be $52 \%$ (40), which is in accordance with the present results. In the same study, which focused on OLT for liver metastases of NET, the authors found certain predictors of poor outcome, including hepatomegaly, age $>45$ years and any amount of resection concurrent with OLT (40). By considering these poor outcome predictors as exclusion criteria, it was possible to achieve a 5-year OS of $60-80 \%$ (40). However, with these strict criteria certain patients that could benefit from OLT would be excluded (40). Furthermore, in other studies, lengthening the diagnosis-to-OLT time interval had a positive effect or had a no negative effect on the outcome of OLT $(40,41)$. In addition, contradictory statements remain to exist on the indications of OLT with regards to the diagnosis-to-OLT interval in liver metastases of NETs $(40,41)$.

In accordance with the natural history and high recurrence rates of the disease, hepatic metastases from NETs could indicate that subclinical disease is already present, and therefore, in the opinion of certain authors, aggressive liver resection cannot be considered curative $(15,37,42)$. In a study conducted by Saxena et al (30), the majority of patients with hepatic metastases from NETs experienced treatment failure after receiving a liver resection. In particular, 57 patients (79\%) developed disease progression at a median time of 23 months, and the liver accounted for the most common site for the progression of disease (69\%) (30). In another multi-institutional study on 339 patients, Mayo et al (37) demonstrated that the majority of liver metastases from NETs originated as carcinoid tumors $(53 \%)$ and, at 5 years subsequent to surgery, the recurrence rate was $94 \%$. In the same study, according with the multivariate analysis, synchronous disease, non-functional NET hormonal status and extrahepatic disease were the most important predictive factors for worse survival (37).

The current literature suggests that surgical resection of hepatic neuroendocrine neoplasms may be associated with favorable outcomes; however, clinical and oncological variables to distinguish the patient cohorts that would benefit most from such aggressive therapy have not been clearly identified. Patients with an increased number of hepatic tumors tend to be managed without surgical resection and patients with synchronous disease are more likely to be treated without surgery (29).

In a previous meta-analysis, an increase in the 5-year OS rate was also observed in patients affected by hepatic metastases from NETs that underwent hepatic surgery (29); however, randomized clinical trials are necessary to more adequately evaluate the effect of surgery on survival of this group of patients.

Liver metastases are frequently encountered in patients with gastrointestinal NETs and are an important factor in the prognosis of the patient. For patients with resectable hepatic disease, the majority of the authors recommend the use of liver resection, as this treatment most likely offers the best long-term outcome. However, the number of patients that can be considered as candidates for hepatic resection is very restricted, and the recurrence of disease following surgery is a common occurrence.

Since no randomized clinical trial has provided meaningful information regarding the sustained advantages of hepatic resection, no certain conclusion on the impact of this aggressive approach can be achieved. Therefore, further studies comparing liver resection alone or in combination with other therapy are recommended to be undertaken. In addition, an accurate evaluation of novel clinical and biological parameters may be useful to improve the identification of patients that may better benefit from hepatic surgical therapy.

OLT appears to be safe and effective in the treatment of selected patients and demonstrates a survival that is comparable with patients treated by hepatic resection; however, additional randomized clinical trials are also required on this subject.

\section{References}

1. Schimmack S, Svejda B, Lawrence B, Kidd M and Modlin IM: The diversity and commonalities of gastroenteropancreatic neuroendocrine tumors. Langenbecks Arch Surg 396: 273-298, 2011.

2. Lawrence B, Gustafsson BI, Chan A, Svejda B, Kidd M and Modlin IM: The epidemiology of gastroenteropancreatic neuroendocrine tumors. Endocrinol Metab Clin North Am 40: 1-18, vii, 2011.

3. Modlin IM, Lye KD and Kidd M: A 5-decade analysis of 13,715 carcinoid tumors. Cancer 97: 934-959, 2003.

4. Oberg K and Castellano D: Current knowledge on diagnosis and staging of neuroendocrine tumors. Cancer Metastasis Rev 30 (Suppl 1): 3-7, 2011.

5. Auernhammer CJ and Göke B: Therapeutic strategies for advanced neuroendocrine carcinomas of jejunum/ileum and pancreatic origin. Gut 60: 1009-1021, 2011.

6. Eriksson B New drugs in neuroendocrine tumors: Rising of new therapeutic philosophies? Curr Opin Oncol 22: 381-386, 2010.

7. Cho CS, Labow DM, Tang L, Klimstra DS, Loeffler AG, Leverson GE, Fong Y, Jarnagin WR, D'Angelica MI, Weber SM, et al: Histologic grade is correlated with outcome after resection of hepatic neuroendocrine neoplasms. Cancer 113: 126-134, 2008.

8. Nikou GC, Lygidakis NJ, Toubanakis C, Pavlatos S, Tseleni-Balafouta S, Giannatou E, Mallas E and Safioleas M: Current diagnosis and treatment of gastrointestinal carcinoids in a series of 101 patients: The significance of serum chromogranin-A, somatostatin receptor scintigraphy and somatostatin analogues. Hepatogastroenterology 52: 731-741, 2005.

9. Mazzaferro V,Pulvirenti A and Coppa J: Neuroendocrine tumors metastatic to the liver: How to select patients for liver transplantation? J Hepatol 47: 460-466, 2007.

10. Norton JA: Endocrine tumours of the gastrointestinal tract. Surgical treatment of neuroendocrine metastases. Best Pract Res Clin Gastroenterol 19: 577-583, 2005.

11. Hellman P, Lundström T, Ohrvall U, Eriksson B, Skogseid B, Oberg K, Tiensuu Janson E and Akerström G: Effect of surgery on the outcome of midgut carcinoid disease with lymph node and liver metastases. World J Surg 26: 991-997, 2002.

12. Janson ET, Holmberg L, Stridsberg M, Eriksson B, Theodorsson E, Wilander E and Oberg K: Carcinoid tumors: Analysis of prognostic factors and survival in 301 patients from a referral center. Ann Oncol 8: 685-690, 1997.

13. Nykjaer KM, Grønbaek H, Nielsen DT, Christiansen P and Astrup LB: Description of patients with midgut carcinoid tumours: Clinical database from a Danish centre. In Vivo 21: 679-684, 2007.

14. Modlin IM, Oberg K, Chung DC, Jensen RT, de Herder WW, Thakker RV, Caplin M, Delle Fave G, Kaltsas GA, Krenning EP, et al: Gastroenteropancreatic neuroendocrine tumours. Lancet Oncol 9: 61-72, 2008. 
15. Gomez D, Malik HZ, Al-Mukthar A, Menon KV, Toogood GJ, Lodge JP and Prasad KR: Hepatic resection for metastatic gastrointestinal and pancreatic neuroendocrine tumours: Outcome and prognostic predictors. HPB (Oxford) 9: 345-351, 2007.

16. Frilling A, Sotiropoulos GC, Li J, Kornasiewicz O and Plöckinger U: Multimodal management of neuroendocrine liver metastases. HPB (Oxford) 12: 361-379, 2010

17. Landry CS, Scoggins CR, McMasters KM, and Martin RC 2nd: Management of hepatic metastasis of gastrointestinal carcinoid tumors. J Surg Oncol 97: 253-258, 2008.

18. Musunuru S, Chen H, Rajpal S, Stephani N, McDermott JC, Holen K, Rikkers LF and Weber SM: Metastatic neuroendocrine hepatic tumors: Resection improves survival. Arch Surg 141: 1000-1004; discussion 1005, 2006.

19. Turaga KK and Kvols LK: Recent progress in the understanding, diagnosis, and treatment of gastroenteropancreatic neuroendocrine tumors. CA Cancer J Clin 61: 113-132, 2011.

20. Klimstra DS, Modlin IR, Coppola D, Lloyd RV and Suster S: The pathologic classification of neuroendocrine tumors: A review of nomenclature, grading, and staging systems. Pancreas 39: 707-712, 2010.

21. Soga J: The term 'carcinoid' is a misnomer: The evidence based on local invasion. J Exp Clin Cancer Res 28: 15, 2009.

22. Rorstad O: Prognostic indicators for carcinoid neuroendocrine tumors of the gastrointestinal tract. J Surg Oncol 89: 151-160, 2005.

23. Sarmiento JM, Heywood G, Rubin J, Ilstrup DM, Nagorney DM and Que FG: Surgical treatment of neuroendocrine metastases to the liver: A plea for resection to increase survival. J Am Coll Surg 197: 29-37, 2003

24. Norton JA, Warren RS, Kelly MG, Zuraek MB and Jensen RT: Aggressive surgery for metastatic liver neuroendocrine tumors. Surgery 134: 1057-1063; discussion 1063-1065, 2003.

25. Chamberlain RS, Canes D, Brown KT, Saltz L, Jarnagin W, Fong Y and Blumgart LH: Hepatic neuroendocrine metastases: Does intervention alter outcomes? J Am Coll Surg. 190: 432-445, 2000.

26. Adani GL, Baccarani U, Risaliti A, Sainz-Barriga M, Lorenzin D and Bresadola F: Right lobe living related graft loss due to intrahepatic multiple arterio-portal fistulas. Transplant Proc 36: 2733-2735, 2004.

27. Strosberg JR, Cheema A and Kvols LK: A review of systemic and liver-directed therapies for metastatic neuroendocrine tumors of the gastroenteropancreatic tract. Cancer Control 18 $127-137,2011$

28. Srirajaskanthan R, Toumpanakis C, Meyer T and Caplin ME: Review article: Future therapies for management of metastatic gastroenteropancreatic neuroendocrine tumours. Aliment Pharmacol Ther 29: 1143-1154, 2009.

29. Bacchetti S, Bertozzi S, Londero AP, Uzzau A and Pasqual EM: Surgical treatment and survival in patients with liver metastases from neuroendocrine tumors: A meta-analysis of observational studies. Int J Hepatol 2013: 235040, 2013.

30. Saxena A, Chua TC, Sarkar A, Chu F, Liauw W, Zhao J and Morris DL: Progression and survival results after radical hepatic metastasectomy of indolent advanced neuroendocrine neoplasms (NENs) supports an aggressive surgical approach. Surgery 149: 209-220, 2011
31. Bonaccorsi-Riani E, Apestegui C, Jouret-Mourin A, Sempoux C, Goffette P, Ciccarelli O, Borbath I, Hubert C, Gigot JF, Hassoun Z and Lerut J: Liver transplantation and neuroendocrine tumors: Lessons from a single centre experience and from the literature review. Transpl Int 23: 668-678, 2010.

32. Sutton R, Doran HE, Williams EMI, Vora J, Vinjamuri S, Evans J, Campbell F, Raraty MG, Ghaneh P, Hartley M, et al: Surgery for midgut carcinoid. Endocr Relat Cancer 10: 469-481, 2003.

33. Glazer ES, Tseng JF, Al-Refaie W, Solorzano CC, Liu P, Willborn KA, Abdalla EK, Vauthey JN and Curley SA: Long-term survival after surgical management of neuroendocrine hepatic metastases. HPB (Oxford) 12: 427-433, 2010.

34. Frilling A, Rogiers X, Malagó M, Liedke OM, Kaun M and Broelsch CE: Treatment of liver metastases in patients with neuroendocrine tumors. Langenbecks Arch Surg 383: 62-70, 1998

35. Coppa J, Pulvirenti A, Schiavo M, Romito R, Collini P, Di Bartolomeo M, Fabbri A, Regalia E and Mazzaferro V: Resection versus transplantation for liver metastases from neuroendocrine tumors. Transplant Proc 33: 1537-1539, 2001.

36. Jaeck D, Oussoultzoglou E, Bachellier P, Lemarque P, Weber JC, Nakano $\mathrm{H}$ and Wolf P: Hepatic metastases of gastroenteropancreatic neuroendocrine tumors: Safe hepatic surgery. World J Surg 25: 689-692, 2001.

37. Mayo SC, de Jong MC, Pulitano C, Clary BM, Reddy SK, Gamblin TC, Celinksi SA, Kooby DA, Staley CA, Stokes JB, et al: Surgical management of hepatic neuroendocrine tumor metastasis: Results from an international multi-institutional analysis. Ann Surg Oncol 17: 3129-3136, 2010.

38. Yao KA, Talamonti MS, Nemcek A, Angelos P, Chrisman H, Skarda J, Benson AB, Rao S and Joehl RJ: Indications and results of liver resection and hepatic chemoembolization for metastatic gastrointestinal neuroendocrine tumors. Surgery 130: 677-682; discussion 682-685, 2001

39. Nave H, Mössinger E, Feist H, Lang H and Raab H: Surgery as primary treatment in patients with liver metastases from carcinoid tumors: A retrospective, unicentric study over 13 years. Surgery 129: 170-175, 2001.

40. Le Treut YP, Grégoire E, Klempnauer J, Belghiti J, Jouve E, Lerut J, Castaing D, Soubrane O, Boillot O, Mantion G, et al: Liver transplantation for neuroendocrine tumors in Europe-results and trends in patient selection: A 213-case European liver transplant registry study. Ann Surg 257: 807-815, 2013.

41. Gedaly R, Daily MF, Davenport D, McHugh PP, Koch A, Angulo P and Hundley JC: Liver transplantation for the treatment of liver metastases from neuroendocrine tumors: An analysis of the UNOS database. Arch Surg 146: 953-958, 2011.

42. Sartori P, Mussi C, Angelini C, Crippa S, Caprotti R and Uggeri F: Palliative management strategies of advanced gastrointestinal carcinoid neoplasms. Langenbecks Arch Surg 390: 391-396, 2005 